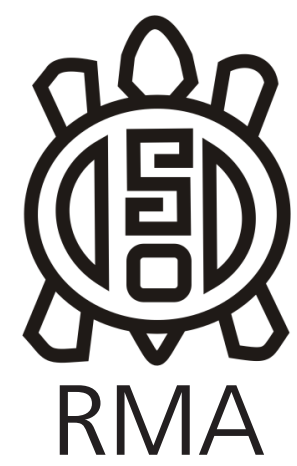

Museología

\title{
Antropología de los museos y representaciones afrodescendientes: perspectivas teóricas, debates y propuestas
}

\author{
Anthropology of museums and representations of African descent: \\ theoretical perspectives, debates and proposals
}

*Eva Lamborghini

*Instituto de Historia Argentina y Americana 'Dr. Emilio Ravignani', Facultad de Filosofía y Letras, Universidad de Buenos Aires, CONICET, Argentina.

E-mail: lamborghinieva@yahoo.com.ar

\begin{abstract}
Resumen
Fuertemente vinculada a la consolidación de los Estados nacionales modernos y al colonialismo, la configuración del museo fue central para la clasificación de identidades y "culturas nacionales" homogéneas, así como para la exclusión de "otros" (externos e internos). En contraposición, y en consonancia con los nuevos contextos multiculturalistas, de reivindicaciones y demandas en términos de etnicidad y luchas de distintas minorías sociales por sus derechos, se espera que los museos actuales puedan dar lugar a una diversidad de identidades silenciadas y/o representadas históricamente desde cánones hegemónicos. Este artículo propone un recorrido sobre la bibliografía crítica de los museos de las últimas décadas, distinguiendo aportes desde la Antropología que dan cuenta de la transformación de estas instituciones en arenas altamente politizadas, donde grupos subalternizados cuestionan las relaciones de poder históricas y dirimen su inclusión y auto-representación. El trabajo finaliza enfocando las representaciones afrodescendientes en Argentina como un terreno particularmente relevante para reflexionar sobre la supuesta transparencia de las relaciones entre cultura, identidad y museos.
\end{abstract}

Palabras clave: Nueva museología; Antropología de los museos; Representaciones; Afrodescendientes, Argentina.

\begin{abstract}
Central to the classification of homogenous national identities and cultures and the exclusion of "others" (external and internal), the museum was strongly linked to the consolidation of modern national states and colonialism. In contrast, and in line with new multiculturalist contexts, demands in terms of ethnicity and struggles of different social minorities for their rights, it is expected that current museums may give rise to a diversity of identities silenced and / or historically represented from hegemonic canons. This article proposes a journey through the critical bibliography of the museums of the last decades, distinguishing some contributions of the Anthropology that give account of the transformation of these institutions in highly politicized arenas, where subalternized groups question the power relations and decide their inclusion and self-representation. Finally, it focuses on Afro-descendant representations in Argentina as a particularly relevant ground for reflecting on and discussing the supposed transparency of the relationships between "culture", "identity" and museum.
\end{abstract}

Keywords: New museology; Anthropology of museums; Representations; Afro-descendants; Argentina.

Desde fines de la década de 1980 y principalmente en la de 1990, se abre un espacio de literatura crítica sobre los museos, conformándose éstos como un campo de estudio. De manera central, esta bibliografía enfatiza la vinculación entre el surgimiento de estas instituciones, la consolidación de los estados nacionales modernos y el colonialismo. La organización y el emplazamiento de museos aparecen desde entonces como factores clave en la clasificación de identidades y "culturas nacionales" homogéneas y en la definición (y exclusión) de "otros" (externos e internos) en la modernidad. Al tiempo que sus varias funciones ideológicas, epistemológicas y de "gubernamentalidad" (Crampton, 2003) son analizadas, se contribuye a la idea de una "nueva museología" (Vergo, 1989, citado en Crampton, 2003) capaz de "redimirse" de su legado de racismo, clasismo y sexismo (Dibley, 2005). 
La Museología crítica, antecedida por la Nueva Museología', y pensada en sentido amplio como el terreno de reflexión sobre estas instituciones, se desarrolla en tiempos de globalización, migraciones, transnacionalismo y aceleramiento de las comunicaciones. La intensificación de estos procesos se corresponde con la crisis de los modelos de integración o cohesión nacional de tipo asimilacionista y la emergencia del Multiculturalismo como nuevo modo de gestionar la diferencia². Un momento en que las identidades y conflictos entendidos bajo el paradigma de las desigualdades de clase cedieron terreno a las reivindicaciones expresadas en términos étnico-culturales y la "cultura" se constituye como forma de autoafirmación identitaria, pero también como herramienta política de lucha por los derechos de sectores socialmente excluidos (Montero, 2012).

En consonancia con estas transformaciones, se espera que hoy los museos puedan dar cuenta de las discusiones contemporáneas sobre la (de)construcción de la nación, la multiculturalidad y las relaciones interculturales, las dimensiones de género y los entrecruzamientos entre diversos clivajes de pertenencia; de género, étnico-

\footnotetext{
1 El movimiento de la Nueva Museología, iniciado en la década de 1970, buscó una ruptura con el museo tradicional. En 1972, tuvo su primera manifestación pública en la Mesa Redonda "La importancia y desarrollo de los Museos en el mundo contemporáneo", organizada por el ICOM [Consejo Internacional de Museos, constituido por la UNESCO en 1946] en Santiago de Chile. En ella, "se reafirmó el papel social del museo y el carácter global de sus intervenciones" (Declaración de Quebec. Principios básicos de una Nueva Museología, 1984. Disponible en: http://museosdesantafe.com.ar/wp-content/ uploads/2014/08/DECLARACION-DE-QUEBEC.pdf).

En 1984, se realizó en Quebec el "I Taller Internacional sobre los Ecomuseos y la Nueva Museología" cuyo resultado fue un segundo documento que expresó la necesidad ampliar los objetivos de los museos más allá de sus funciones tradicionales, ligadas a la identificación, conservación y educación, recurriendo a nuevos conceptos y estrategias de participación, interdisciplinariedad, comunicación y desarrollo de la población.

En 1985, se fundó en Portugal el Movimiento Internacional para la Nueva Museología (MINOM), adherido al ICOM, cuyos objetivos y principios continuaron en la línea de trascender las funciones tradicionales de los museos.

2 Excede a los propósitos de este trabajo un estado de la cuestión sobre los análisis del Multiculturalismo. A manera de encuadre, siguiendo a Montero (2012), las mutaciones que abarca refieren al lugar que toma el problema de la coexistencia de las "diferencias" en un mismo espacio político nacional y cómo esta cuestión pasa a exigir nuevas modalidades de gestión y de compartir el espacio público, una vez agotadas o en crisis los modelos y utopías asimilacionistas del pasado (Montero, 2012)

En general, la descripción del Multiculturalismo en América Latina abarca una serie de cambios relacionados que ofician de marco para la incorporación en las agendas nacionales de temáticas indígenas y de las poblaciones de origen africano, llevándose a cabo reformas constitucionales que contemplan derechos específicos - principalmente-, pero no sólo, el derecho a la diferencia. Entre los cambios que confluyen con/en las políticas de reconocimiento en estos nuevos marcos normativos podemos mencionar: la búsqueda de legitimidad de los Estados post-dictatoriales, las reformas neoliberales de achicamiento del Estado; la nueva injerencia de organismos multilaterales de financiamiento; así como también los procesos "desde abajo" de formación de los nuevos movimientos sociales etnopolíticos (ver Agudelo, 2010).
}

raciales, de clase social, etc. En parte, esto se traduce en la mutación de los museos en arenas altamente politizadas donde grupos autoidentificados étnicamente y minorías sociales antes excluidas, invisibilizadas y/o representadas desde cánones hegemónicos, cuestionan relaciones de poder históricas, aún vigentes, y dirimen su inclusión y auto-representación.

Teniendo como base este estado de situación general sobre la museología crítica, el presente artículo se propone trazar algunas de las variables principales a través de las cuales en la bibliografía contemporánea -y desde los aportes de la Antropología más específicamente-, se reflexiona, debate y elaboran propuestas sobre los museos y las representaciones museográficas ${ }^{3}$, para finalmente problematizar algunas relaciones entre representaciones afrodescendientes y museos en el contexto argentino. Para ello, en primer lugar, se reseñan los aportes fundamentales de la bibliografía contemporánea sobre las intersecciones entre la Antropología y los museos, y la Antropología de los museos. En una segunda instancia, se desarrollan algunos lineamientos respecto del lugar de los museos en las repúblicas latinoamericanas en general y, específicamente, sobre la representación de la pretendida "blanquedad" y la otredad interna en los museos argentinos, conforme a los discursos hegemónicos de representación de la nación. Finalmente, retomando las discusiones sobre África en la museología clásica y contemporánea, en un tercer apartado se avanza sobre temáticas relativas a la Antropología de los museos y la(s) (auto)representación(es) africanas y afrodescendientes en Argentina, un país en el que históricamente se ha invisibilizado a la población de ascendencia africana en la construcción de la nación, así como negado el racismo y la desigualdad estructural que opera bajo criterios raciales. Este foco tiene por objetivo la búsqueda de propuestas que puedan contribuir a la construcción de representaciones afrodescendientes más ricas -menos estereotipadas pero también menos esencializadas- en una sociedad que aún se considera de ascendencia "blanca-europea" pero donde, al mismo tiempo, coexiste un marco favorable a las demandas de grupos subalternizados disputadas en el terreno de la cultura. Poniendo de relieve las tensiones del Multiculturalismo en torno a la multiplicación de las diferencias culturales desde criterios de autenticidad, proponemos que las representaciones afrodescendientes en Argentina se presentan como un ámbito particularmente relevante para reflexionar sobre la supuesta transparencia de las relaciones entre cultura, identidad y museo.

Si los museos se han convertido en espacios de masas destinados a la comunicación y la educación de vastas audiencias, este recorrido insiste sobre la imposibilidad

\footnotetext{
3 En este sentido, las reflexiones sobre los museos están más estrechamente relacionadas con los museos etnográficos e históricos, si bien algunas de ellas se extienden a otro tipo de museos, como los de ciencias naturales, etc.
} 
de pensar las tecnologías de representación museográfica como neutrales u objetivas.

\section{La antropología y/de los museos}

La investigación sobre las formas en que las exhibiciones museográficas han definido la "cultura" y modelado las visiones sobre la diferencia cultural ha sido crucial en el establecimiento de los museos como un tema de estudio importante de la Antropología (Moser, 2010). Ya en 1993, Jones observaba que las discusiones sobre las prácticas museísticas desde los '80 ponían de relieve los temas debatidos dentro de la Antropología en general: la naturaleza de la autoridad etnográfica; la creación de tradiciones; los enfoques coloniales y postcoloniales sobre la representación de "otras" culturas y la responsabilidad ética de los antropólogos (Jones, 1993).

Así como la Antropología y los museos se apoyaron mutuamente en sus comienzos, las transformaciones en la historia de la disciplina y los cambios en las prácticas de los museos contemporáneos y los paradigmas que los informan trabajan hoy en la reparación de sus respectivos "pecados de origen". Enfatizando en los aportes realizados desde la Antropología, a continuación, identificaremos algunos de los puntos nodales que se destacan en la bibliografía crítica (no técnica) contemporánea sobre museos.

\section{Museos, nacionalismos y colonialismo}

Uno de los aspectos salientes de esta bibliografía crítica es la reconstrucción de los orígenes modernos de los museos y su historia durante gran parte del siglo XX. Aquí es central la ligazón entre su surgimiento y la consolidación de los estados nacionales modernos, la construcción de identidades nacionales y el colonialismo ${ }^{4}$.

Según el trabajo influyente de James Clifford (1997: 192-193) los "museos colección" europeos del siglo XIX actuaron estructurando los itinerarios de los objetos desde la periferia colonial ("sitios de descubrimiento") hacia el centro metropolitano ("puntos de convergencia").

La formación y exhibición de colecciones de objetos que proveyeran sentidos a un pasado común y remoto fueron fundamentales para la representación del Estado y para los procesos de imaginación de identidades nacionales que los museos apuntalaron (Santos, 2003). Los estados europeos construyeron las raíces históricas de sus sociedades a través de la apropiación y exhibición de la cultura material de las "civilizaciones antiguas" (griega, romana, egipcia), respecto de las cuales cimentaron sus "mitos de descendencia" (ídem). La posesión de objetos de otras culturas coadyuvó asimismo a representar diferencias

\footnotetext{
${ }^{4}$ Un antecedente fundamental en el planteo abierto y crítico sobre los orígenes de los museos como herramienta del colonialismo europeo, es el trabajo de Hugues De Varine (1974), arqueólogo, historiador y museólogo francés, director de ICOM entre 1965 y 1974.
}

culturales y raciales (siguiendo tipologías) que, basadas en la ciencia de la época, resaltaban la superioridad cultural tecnológica y moral europea, en una secuencia evolutiva en donde el Estado-Nación era el signo final del progreso (Macdonald, 2003). En síntesis, como indica Coombes (1994, citado en Crampton, 2003), en la Europa moderna los museos nacieron y se desarrollaron como proyectos de fortalecimiento simultáneo de identidad nacional e imperial. Los espacios de exhibición fueron funcionales a los Estados para fomentar una nacionalidad unificada e ideologías imperialistas que apoyaran las políticas de ultramar. Se convenció a las clases trabajadoras de que sus intereses estaban mejor representados mediante la expansión del imperio, mientras que los predicamentos sobre el "progreso" en museos como el Louvre o el British Museum estaban basados en la explotación colonial (Averbach 1999, citado en Dibley, 2005).

En esta línea de reflexión sobre el papel de los museos en las fronteras interiores de clase, etnicidad (y género), Tony Bennett, otro estudioso influyente en este campo, propone hacer auto-conscientes y explicitar los mecanismos que nacen con el museo, para luego desmantelarlos y establecer nuevas relaciones (Bennet, 1995, citado en Dibley, 2005). Como otros autores más tarde, puso de relieve una lectura de los museos a partir de Foucault y su noción de "bio-poder", Ilamando la atención sobre algunos elementos de gubernamentalidad, como la introducción de prácticas "civilizadas" alejadas de modos de comportamiento "inapropiados" ${ }^{5}$. Según esta crítica, los museos pueden entenderse como dispositivos disciplinarios; como programas destinados tanto al ordenamiento del material exhibido como de la sociedad, es decir; a la producción de determinados sujetos.

\section{Desmantelando pecados de origen: La representación y la clasificación en/y de los museos}

La Antropología de los museos ha señalado, de manera general, el problema de la "descontextualización" -es decir, el hecho de que la mayor parte de los objetos exhibidos hayan sido creados en y para contextos nada parecidos a un museo (Vogel, 1991)-, cuestión que se agudiza en el caso de los bienes culturales ${ }^{6}$. Sin embargo, aunque no desvinculado del problema anterior, una de las líneas de investigación predominante gira en torno al análisis de la construcción de representaciones. El extendidamente citado trabajo de Ames (1991) señaló

\footnotetext{
${ }^{5}$ Según Bennet, el museo, al igual que la institución carcelaria que observa Foucault, está constantemente demandando reformas. Esto resulta de la disyunción entre dos discursos de igualdad que vienen del siglo XIX -accesibilidad y representación igualitarias- y los modos efectivos de operar (según una racionalidad política específica) (Bennet, 1995, citado en Dibley, 2005).

${ }^{6}$ Khan (1995) trabaja el concepto foucaultiano de "disonancia heterotópica" al analizar los museos como espacios donde se produce la domesticación y el dislocamiento —el "fuera de lugar"_ de los objetos exhibidos. Sobre el significado atribuido a estos últimos, la autora se pregunta si proviene del contexto cultural "original", o de la función de "cruce- cultural" de estas instituciones.
} 
la relación entre representación y museos como un problema político; si la representación es un acto político, planteó, el museo no puede reclamar más privilegios de neutralidad o universalidad. La representación, el patrocinio y la curaduría son actos políticos. Trabajar en un museo es un acto político (Ames, 1991: 13).

Como indica Crampton (2003), para analizar el rol ideológico de los museos es importante no sólo interrogar su función simbólica y gubernamental, sino también atender a los contenidos específicos de las exhibiciones y la producción de significados dentro de estos recintos: "Ios museos proveen espacios de representación investidos y delineados por un abanico de saberes disciplinarios que dividen culturas y pueblos, dándole expresión visual a los discursos de la nación, raza, progreso, etc." (Crampton, 2003: 221, trad. propia).

De esta manera, las reconstrucciones detalladas de las instalaciones, catálogos, exhibiciones y la "crítica al Primitivismo" de los museos agregaron un nivel importante al entendimiento de las tecnologías de representación propias de los museos (Jones, 1993). Sin embargo, el llamado de atención sobre la política en/de las representaciones fue mucho más lejos, llegándose a plantear "meta- museos" que representen su propio modo de representación (Khan, 1995). Autores como Pieterse (1997, citado en Lleras Figueroa, 2009) proponen que las muestras museográficas reflejen la lógica de la alteridad y desenmascaren la representación como herramienta de poder, incluso haciendo de ella un objeto para mostrar. Dentro de esta línea, se intenta hacer visible la arbitrariedad del proceso bajo el cual los "objetos etnográficos" han sido "producidos" (Saloni, 2000). De manera general, se trata de hacer explícitos los procesos de curaduría, de selección y de negociación de una exhibición (Lleras Figueroa, 2009).

Del mismo modo que se ha enfocado la relación entre museos y representación, se han examinado y puesto en cuestión las tareas de clasificación inmanentes a estas instituciones (Steiner, 1995), destacándose también el carácter político de estas operaciones. Como indica Khan (1995), los museos son "casas clasificadoras" y por eso devienen instituciones de conocimiento y tecnologías de poder:

"en la colección de ciertos objetos y no otros, en su descripción y nomenclaturas, en su exhibición de una manera y no de otra, y en la construcción de contextos, los museos establecen sentido de autoridad. Influencian las definiciones de tradición y herencia, el estatus de categorías analíticas como arte, cultura y área cultural y la importancia de valores sociales e ideologías políticas." (Khan, 1995: 324, trad. propia).

Ludmilla Jordanova (1989, citada en Crampton, 2003) distingue tres niveles (relacionados) de clasificación que se pueden encontrar en los museos modernos de acuerdo con:

1. sus contenidos principales (los museos son de "arte", "antropología", "geología", "historia natural", "ciencia", etc. $)^{7}$;

2. su organización interna (por temas, por áreas culturales nacionales, por periodos históricos, etc.) y

3. los objetos que presentan (la clasificación y los textos que acompañan a cada objeto produciendo significado).

Detallando y discutiendo esta clasificación, Crampton (2003) señala que si bien las fronteras entre las categorías organizativas del primer nivel (el de los contenidos de los museos: de "antropología", de "arte", de "historia natural") pueden parecer naturales, su construcción y mantenimiento es un acto político muy debatible, pues no hay nada inherente a los objetos que los haga corresponder a uno u otro régimen de clasificación. La mera ubicación de determinado grupo étnico o patrimonio cultural en ciertos museos ("historia natural", "antropología", etc.) los aleja (o aún quita) de la "civilización", de la "historia" y de la "cultura" y los acerca a la "naturaleza" y a estadios "primitivos" de la "evolución".

Otros autores también han reflexionado acerca de la naturalización de las categorías que imperan en este primer nivel. Una clasificación que trajo tempranas reflexiones fue la distinción entre "arte" versus "objeto etnográfico". Ames (1991) sostiene que la división entre arte y objeto etnográfico remite a diferencias políticoideológicas y, particularmente, clama por "liberar de su destino etnológico" (de los museos de antropología) a los trabajos creativos de las poblaciones originarias, ya que de esta manera nunca reciben el mismo trato y consideración que otras tradiciones "nacionales". Asimismo, observa los problemas que se generan cuando las personas o los objetos cruzan las fronteras como, por ejemplo, las disyuntivas suscitadas por el arte o los artistas "nativos"8. Otra cuestión recurrente respecto de la exposición de objetos etnográficos es el problema de la temporalidad. Elaborando el segundo nivel de Jordanova, el de la organización interna de los museos, Crampton (2003) señala que las periodizaciones no suelen ser inocentes, ya que ubican a determinados grupos o patrimonios culturales -a través de la clasificación o la ubicación espacial del museo- principalmente en determinados momentos o etapas de las historias nacionales, que a su vez siguen una narrativa evolucionista mayor. Los museos expresan así la historia de la nación espacialmente, guiando a los visitantes de un período al próximo, de

\footnotetext{
${ }^{7}$ También pueden clasificarse de acuerdo con un tema principal (reflejando la obra de algún/os escritor/es, artista/s, músico/s) o por su ubicación geográfica (museos regionales).

${ }^{8}$ Que oscilan entre ser definidos como no "nativo/s", o no "arte/ artistas".
} 
un evento al siguiente. El presente -dominado por determinado/s grupo/s y patrimonio/s- se representa espacialmente como emergiendo de una inteligible y secuencial serie de eventos en el pasado, en el cual se ubican, mayoritariamente, otros actores, grupos y patrimonios. En esta misma línea, Khan (1995) resume la correspondencia construida entre determinado tipo de objetos y un mundo "tradicional" cerrado y elevado sobre el que se erige un pasado genérico, un tiempo vacío y eterno. Como salida a estos pasados estáticos y presentes sin explicación, la autora se pregunta por la posibilidad de desbancar estereotipos y exhibir la transformación cultural como un proceso en marcha, dinámico y creativo, estableciendo conexiones entre los eventos del pasado y la vida del presente (Khan, 1995: 335).

Por lo tanto, aunque sin pretender ahondar en cuestiones técnicas, hay que remarcar que todo lo relativo a la forma en que se presentan los materiales hace al "guión curatorial" y, de esta manera, a determinado discurso o visión que quiere ser transmitida. Esto sucede tanto en el segundo nivel de Jordanova, el de la organización interna del museo (o del estilo y tipo de exhibición para poder abarcar exposiciones temporales también), como en el tercero, el de los objetos que son presentados, clasificados y etiquetados. Las etiquetas y los textos que acompañan a los objetos revelan, producen o -cuando menos- sugieren su significado. Como señala Crampton (2003), la reificación de determinadas categorías étnicas o raciales, que no necesariamente coinciden con las autoidentificaciones de los grupos -o que reflejan su transitoriedad y multiplicidad-, pueden incentivar o ratificar, más que disminuir, procesos de segregación social. Aunque este autor se refiere principalmente al caso sudafricano y al reforzamiento de ideologías del apartheid, el ejemplo se puede aplicar a muchos otros contextos actuales, aún en tiempos de apreciación del Multiculturalismo, en tanto doctrina que encuentra sus virtudes políticas en la propia producción de las diferencias (Sartori, 2001, en Montero, 2012).

La bibliografía crítica también suele referirse a la distinción entre los guiones curatoriales orientados en base a objetos o en base a ideas (Moser, 2010) siendo la primera forma frecuentemente vinculada con la permanencia de paradigmas antiguos donde los objetos eran sacralizados y considerados fines en sí mismos, en lugar de medios para determinados fines sociales (Pérez Ruiz, 1998; Pérez Gollán y Dujovne, 2001) ${ }^{9}$. En cambio, la orientación por ideas no sólo está asociada a criterios más interpretativos y didácticos, sino que además se relaciona con la "multivocalidad" (Saloni, 2000), es decir; la posibilidad de contar con diferentes registros e interpretaciones, en lugar de

\footnotetext{
${ }^{9}$ En la línea crítica de las exposiciones centradas en objetos y los modelos clasificatorios aparejados se encuentra el trabajo de Jacques Hainard, etnólogo suizo, quien fuera director durante veinticinco años del Museo de Etnografía de Neuchâtel y uno de los intelectuales que dio origen a la "museología de ruptura".
}

una línea definida o una visión cerrada que empieza y termina en la intención de la institución o del curador. Esto, a su vez, se relaciona con uno de los cambios centrales en los museos de las últimas décadas; el rol cada vez más activo y crítico adjudicado a las audiencias.

Los museos como sitios de disputa y negociación: El trabajo colaborativo en tiempos de Multiculturalismo A diferencia de los "museos colección" del siglo XIX, Clifford (1997) se refiere a los museos contemporáneos como "zonas de contacto" donde el objeto es reposicionado como sitio de un proceso de negociación de significado y valor. Siguiendo a Clifford, Dibley plantea que "la insurgencia de las voces subyugadas" ha sido fundamental para la impugnación de los reclamos universales del museo como frontera y colección (Dibley, 2005: 8).

Si una de las líneas dominantes de investigación en la Antropología de los museos ha sido el estudio de las representaciones y clasificaciones, otro eje principal lo constituyen las respuestas de las comunidades a cómo se ven (des)representadas en los museos históricos o culturales (Yelvington, Goslin y Arriaga, 2002). Estas respuestas van desde cuestionamientos, boicots y desmantelamientos de muestras, hasta procesos de colaboración y comités co-organizados entre especialistas en museos, cientistas sociales y comunidades étnicas (entre quienes hay cada vez más especialistas) para organizar nuevas muestras o reformar previas. Los trabajos de Ames fueron de los primeros en dar cuenta de estas negociaciones y del pasaje de "los pueblos no representados y marginados" desde la consulta a la toma de decisiones respecto de las (auto)representaciones en una muestra, sala o museo, junto con la creciente demanda por romper y cruzar barreras tradicionales occidentales de arte/artefacto/artesanía tradicional/ moderno antropología/arte/ historia (Ames, 1991).

Esta irrupción de las voces subalternas en los museos contemporáneos ha sido fundamental para los cambios de las prácticas museográficas convencionales y las reflexiones teóricas que las acompañan. En el apartado sobre la relación entre política y exhibiciones, Jones (1993) observa que el diálogo entre nativos y curadores ha sido importante en la crítica de temas tales como: la omisión de los artistas indígenas contemporáneos; la falta de consulta a las comunidades nativas locales; la exposición de objetos obtenidos bajo sospecha; el tratamiento histórico tergiversado y el uso por parte de los curadores del concepto de "cultura" junto con su particular ignorancia de temas políticos contemporáneos (Jones, 1993: 209, trad. propia).

Procesos complejos como las migraciones y el transnacionalismo, la globalización y el Multiculturalismo desafían los criterios "nacionales" de los museos tradicionales (Steiner, 1995). Los procesos de etnicización 
y movilización cultural y política de grupos étnico-raciales al interior y a través de las fronteras nacionales han posibilitado, entre otras transformaciones, el cambio del museo de un sitio de memorias hegemónicas, a un espacio para la confrontación, negociación y empoderamiento de grupos subalternizados. Un campo de fuerzas con lugar para la construcción de memorias alternativas y antihegemónicas (Pérez Ruiz, 1998) y para la reivindicación de nuevas identidades (Macdonald, 2003).

Claro que, con el tiempo, también se han emitido juicios sobre las limitaciones de la "colaboración nativa". En esta línea, Dubin (2002, citado en Mithlo, 2003) opina que "la auto-representación tribal" de la "nueva museología" aparece como una "solución segura y fácil ante la crisis de autoridad contemporánea", mientras que "este traspaso de responsabilidad no garantiza representaciones más certeras o contra-hegemónicas ya que "distintas palabras son usadas para transmitir la misma información" (Mithlo, 2003: 157, trad. propia). Además, los miembros locales de las comunidades étnicas pueden sostener distintos puntos de vista (Jones, 1993) ya que como sabemos, ni los grupos ni los movimientos sociales son homogéneos. Steiner (1995) observa que, a la contradicción general de los Museos Nacionales -la distancia entre los símbolos de representación nacional y los nacionales a quienes supuestamente representan-, hay que agregar los posibles desacuerdos dentro de determinado grupo sobre el contenido y la naturaleza de las imágenes propias y de la identidad nacional. Esta perspectiva crítica remite al problema atravesado por la Antropología en general señalado por Montero (2012), por cuanto que, al tiempo que la crítica deconstruccionista y poscolonial "diluye" el concepto de "cultura" en términos de negociaciones contextuales de significados, la idea esencialista de cultura es apropiada por el campo político, "tornándose al mismo tiempo, un instrumento de autoafirmación identitaria y un lenguaje jurídico de atribución de derechos" (Montero, 2012: 82).

Este tipo de problematizaciones son reflejadas, asimismo, en la bibliografía crítica sobre el Multiculturalismo, en gran parte formulada como una reacción explícita a las políticas de reconocimiento de, y apoyadas por, los Estados y coordinadas con intereses de instituciones multilaterales de desarrollo. Son extensos los trabajos que señalan los dilemas y contradicciones de este nuevo paradigma en torno a la multiplicación de las diferencias culturales desde criterios de autenticidad y la reproducción de la desigualdad en el acceso a una ciudadanía plena. Varios análisis han señalado que la inclusión multiculturalista de algunos esconde mecanismos que trabajan para seguir denegando soberanía a otros (Greene, 2007; Hale, 2004). De manera más general, las discusiones teóricas del Multiculturalismo ponen de relieve las tensiones entre la redistribución y el reconocimiento (Fraser, 1997).

En el campo de estudios referente a la institución museo, algunos autores han argumentado que, así como el
Multiculturalismo ofrece un contexto favorable frente a los ideales de homogeneidad nacional del pasado, también conlleva sus peligros. Estos están en gran medida ligados a la mercantilización de la cultura, dado el rol que cumple la orientación (cada vez mayor) de los museos hacia el mercado. Se advierte el riesgo de sustituir a estas instituciones por centros culturales que reiteren las políticas multiculturalistas de "tolerar" la diferencia y el mecanismo del espectáculo multicultural de la nación (Message 2006, citado en Lleras Figueroa, 2009). Como argumenta Macdonald (2003), el riesgo del Multiculturalismo remite a que la diferencia sea fijada o musealizada por medio de la identificación de comunidades y tradiciones discretas y esencializadas.

\section{Los museos en las nuevas repúblicas latinoamericanas y la "blanquedad" de la nación en los museos argentinos}

Si los museos de las metrópolis occidentales del siglo XIX fueron claves en la clasificación y construcción de identidades y "culturas nacionales" homogéneas y en la definición (y exclusión) de "otros" (externos e internos), estos mecanismos se reprodujeron en las colonias. Por lo tanto, así como se abrió una corriente de investigación de orientación histórica sobre museos y colecciones particulares en el seno de las metrópolis, crítica de su vinculación con el colonialismo, se abrió otra sobre los museos nacionales de los países de origen colonial, crítica de sus discursos hegemónicos (Pérez Ruiz, 1998).

En los Estados poscoloniales, los museos fueron parte de la herencia política de los Estados colonizados, con sus tecnologías de representación creadoras de profundidad histórica y memorialización y sus prácticas de construcción de la nación moderna (Anderson, 1993). En cuanto a los museos de las repúblicas latinoamericanas independientes, éstos se modelaron de acuerdo con los criterios de sus contrapartes europeos; fueron centros difusores de hábitos modernos y civilizados, proyectaron una imagen civilizada al exterior (Pérez Gollán y Dujovne, 2001), funcionaron como monumentos a los Estados-Nación y contribuyeron a la invención de identidades nacionales. Sin embargo, también produjeron sus propias especificidades (Santos, 2003; Lopes y Podgorny, 2001). Así, mientras los museos europeos construyeron relaciones de descendencia con las "civilizaciones antiguas" y proclamaron su pasado y sus valores como universales (Santos, 2003), la imaginería de los museos latinoamericanos estuvo basada en la naturaleza, impronta que influyó en su historia y en la formación de sus colecciones (Santos, 2003; Lopes y Podgorny, 2001). El espectáculo de la naturaleza ofreció la posibilidad de construir pasados nacionales ligados a pasados universales profundos. En América Latina, los museos de historia natural, con sus grandes colecciones paleontológicas, fueron sitios de ciencia, de invención de identidades nacionales y símbolos mismos de identidad nacional. 
Los museos como "centros de nacionalización de la naturaleza" (Lopes y Podgorny, 2001) y los relatos sobre la extinción o casi extinción de las poblaciones indígenas originarias -de las que debían registrarse y preservarse vestigios- fueron de la mano. Lopes y Podgorny (2000: 115) advierten para los museos de Brasil y Argentina que la tarea de construir una identidad nacional fue realizada tanto explorando los territorios a ser anexados después de su conquista, como asignándole valor a esos objetos coleccionados como dignos de ser mostrados y legitimando las políticas de exterminio.

En Argentina, los museos también introdujeron prácticas modernas $y$, basados en las teorías darwinistas de selección natural que dieron apoyo a narrativas y prácticas racistas, se vieron en la tarea de construir identidades nacionales y definir un pasado común frente a poblaciones autóctonas deslegitimadas y grandes contingentes de inmigrantes europeos. Pero, así como las sociedades latinoamericanas no construyeron ideologías nacionalistas uniformes, los museos latinoamericanos no representaron los "mitos de descendencia" de la nación de igual modo. En el caso argentino, la museología representó el ideal de "blanquedad", que reemplazó en su manera más brutal -en la construcción de la nación a la que representa- al de mestizaje prevaleciente en otras naciones latinoamericanas (Frigerio, 2006). Como indican Pérez Gollán y Dujovne (2001), en el contexto argentino el esquematismo clasificatorio resultó en la división entre museos de Antropología, dedicados al pasado indígena, y museos de Historia, destinados al pasado europeo. Siguiendo a los mismos autores, el primer museo de Antropología separado por completo de la historia natural fue el Museo Etnográfico de la Universidad de Buenos Aires (ME) en 1904. Desde la investigación, el ME se dedicó a la formación de un patrimonio pre-histórico para la nación argentina en base a poblaciones indígenas que, según la visión del momento, estaban poco evolucionadas y prontas a extinguirse. En esta división entre museos antropológicos y museos históricos, las sociedades indígenas fueron representadas en un pasado distante y excluidas de la historia y del presente de la nación, mientras que el lugar asignado a los y las africanas esclavizados/as y su descendencia afroargentina fue nulo. Por lo demás, y en sintonía con las reflexiones académicas esbozadas en los apartados anteriores, varios análisis locales acompañan algunas de las reformas museográficas dirigidas a reparar las exclusiones y discursos hegemónicos del pasado $^{10}$.

\section{África en los museos y los dilemas de la representación afrodescendiente en Argentina}

\footnotetext{
10 En Buenos Aires, dichos estudios desde la Antropología (y/o la Antropología Histórica) están centrados mayormente en el Museo Etnográfico (Universidad de Buenos Aires) y su reestructuración desde fines de los '80 (Pérez Gollán, 1997; Pérez Gollán y Dujovne, 1996, 2001; Roca, 2008; Pegoraro, 2010). Trabajos como los de Bayardo (2005) analizan cambios en otros museos, como en el re-denominado "Museo de Arte Popular José Hernández".
}

Dentro del campo de estudios crítico sobre los museos, en las últimas décadas se gesta una bibliografía específica que cuestiona las exposiciones destinadas al conocimiento y las representaciones sobre África -y Afro(latino) américa-, así como se organizan numerosas muestras enfocadas en la superación de las representaciones y clasificaciones convencionales que han modelado la imaginación popular sobre este continente. Como resume Arnoldi (1999), esta bibliografía recorre cuestiones como las prácticas históricas de apropiación de objetos africanos en colecciones occidentales y su subsiguiente re-contextualización e interpretación en exposiciones públicas $^{11}$; las relaciones de poder y las políticas de representación. Los enfoques contemporáneos subrayan la necesidad de incorporar temas de la diáspora africana y discuten las representaciones esencialistas ligadas al paradigma primitivista y evolucionista, y las visiones reduccionistas de las culturas africanas ${ }^{12}$. Además, desde la década de 1990 comienzan a realizarse exhibiciones innovadoras que ponen el foco en la audiencia (y sus proyecciones sobre África) o en el museo mismo (las maneras en que esta institución ha clasificado y exhibido la cultura material africana en el siglo pasado) (ver Vogel, 1991). Asimismo, dentro del panorama de negociación entre museos, ciencias y "nativos", muestras africanas que dieron lugar a grandes controversias -tanto de profesionales africanistas como de las comunidades africanas y africanas-americanas- fueron desmanteladas (ver Jones, 1993 y Arnoldi, 1999). De manera general, esta bibliografía da cuenta de que la paulatina inclusión de representantes de la diáspora africana en el proceso de toma de decisiones respecto de las (auto)representaciones en una muestra, sala o museo, viene generando interesantes procesos colaborativos.

Pensando ahora acerca de las posibilidades locales de representación afrodescendiente, teniendo en cuenta las reflexiones de museología crítica en general y de la dedicada a África en particular, nos interesa dar cuenta de algunos de los emprendimientos en esta materia y esbozar una serie de propuestas que puedan contribuir a la construcción de representaciones ricas -no estereotipadas ni esencializadas- de las poblaciones afrodescendientes en Argentina ${ }^{13}$.

Probablemente una buena manera de comenzar sea plantear algunos interrogantes respecto de la

\footnotetext{
${ }^{11}$ Algunos trabajos se dedican al problema contemporáneo del tráfico ilegal y las disposiciones internacionales al respecto, ver por ejemplo Udvardy, Giles y Mitsane, et. al. (2003)

${ }^{12}$ Básicamente, la representación de un África religiosa (en contraposición a un occidente secular), la idea de África uniforme y estática, los enfoques "whole África" y las dicotomías entre "África tradicional" y "África contemporánea", así como entre África rural y África urbana.

13 Para un panorama y revisión sobre el proceso de renovación y consolidación de un campo interdisciplinario de estudios y reflexión sobre afrodescendencia en Argentina, ver Lamborghini, Geler y Guzmán (2017).
} 
"representación (de los) afrodescendiente(s)" utilizando los tres niveles de clasificación de los museos y sus materiales según Jordanova (1989), expuestos en el primer apartado.

Recordándolos brevemente, niveles diagramados de acuerdo con:

1. sus contenidos principales: si son de "arte", "antropología", "geología", "historia natural", "ciencia", etc.;

2. su manera de organización interna: por temas, por áreas culturales nacionales, por periodos históricos, etc. y 3. los objetos que presentan y la clasificación y significación/indicación que se realiza de los mismos.

Con respecto al primer nivel, el de los contenidos principales de los museos, es claro que la ubicación principal de representaciones sobre, o de material producido por, los afrodescendientes en uno u otro tipo de museo trae consecuencias sobre la manera en que pueden ser presentados y verse o sentirse integrados o no al cuerpo de la nación. Así, su ubicación o figuración principalmente en el Museo Etnográfico los presentaría inequívocamente dentro de los "otros internos", en el Museo Histórico como algo del pasado (pero al menos dentro del pasado de la nación), mientras que una ubicación dentro de algún museo de cultura popular puede llevar a una descontextualización de cualquier artefacto allí exhibido. Es bastante improbable, al menos por ahora, que alguna obra artística afroargentina pueda aspirar a integrar el canon que la autorice a ser exhibida en el Museo de Bellas Artes, aunque esto no significa la ausencia de representaciones sobre y autorrepresentaciones afrodescendientes en el arte plástico argentino, sino la presencia de un corpus invisibilizado y disperso (ver Ghidoli, 2016).

De todas maneras, dada la (aún) persistente invisibilización del colectivo, de su patrimonio, su historia y de sus aportes a la "cultura nacional", cualquier inclusión -aún a modo de "otro interno"-, como un grupo con algún tipo de protagonismo que permita visibilizar su ingreso a un museo de culturas populares puede ser considerado ciertamente como un avance.

Respecto del segundo nivel, el de la organización interna de los museos y exhibiciones, y centrándonos en los probables guiones curatoriales que pueden orientar su inclusión en museos, resaltaríamos en principio la necesidad -que consideramos preferible en general, sin importar el grupo o tema en cuestión- de orientación en base a ideas más que en base a objetos, ya que esto puede llevar (aunque sin duda no necesariamente) a su fetichización y descontextualización.

Según nuestro conocimiento actual -que es reducido en este aspecto específico- no son tantos los objetos afro-argentinos o producidos por ellos que puedan ser considerados "musealizables" según los criterios vigentes ${ }^{14}$. En tanto el trabajo de investigación en el terreno de los objetos con la profundidad histórica o la "autenticidad" requerida está en pleno desarrollo, se torna indispensable recurrir principalmente a fotografías, testimonios orales, videos o imágenes de distintas épocas para hacer visible su historia y presencia, teniendo en cuenta la complejidad del tema; la no transparencia de las imágenes, las relaciones entre imagen y discurso en general, y en cuanto a las imágenes racializadas en particular (Lamborghini y Geler, 2017) ${ }^{15}$.

Un aspecto fundamental del diálogo museo-visitantes en este caso comprende necesariamente el cuestionamiento y la movilización de su sentido común sobre la población afrodescendiente en/de Argentina. El primero y principal prejuicio que la sola presencia de una muestra o sala polemizaría es la noción arraigada de que esta población, o bien nunca existió, o dejó de existir hace siglos, o que sus aportes fueron insignificantes. Pero también sería importante discutir otros prejuicios que contribuyen a representaciones estereotipadas, que van desde la total victimización (a menudo ligada a la esclavitud), al encasillamiento de la población afrodescendiente como personas alegres y siempre dispuestas a la música.

Si hasta la primera década del siglo XXI las representaciones afrodescendientes y los museos argentinos habían carecido casi por completo de intersecciones entre sí, desde 2010 (en un momento en el que el proceso de revisibilización afrodescendiente local ya llevaba más de una década) comenzaron a implementarse desarrollos interesantes, varios de los cuales van en las direcciones señaladas. Una de las experiencias destacadas en este sentido es el trabajo en torno a la visibilización de las poblaciones africanas esclavizadas en las estancias jesuíticas de Córdoba, de las cuales los Museos de las Estancias Jesuíticas de Alta Gracia y de Jesús María han sido pioneras ${ }^{16}$

Con respecto a la ciudad de Buenos Aires, aunque no pretendemos elaborar un análisis exhaustivo de los emprendimientos de matiz museográfica realizados hasta ahora, anotaremos a continuación algunos de los

\footnotetext{
14 Para una reflexión respecto de las dificultades en el campo de la Arqueología y una exposición sobre el trabajo en el sitio Arroyo de Leyes en la ciudad de Santa Fe la Vieja, ver Schávelzon y Zorzi (2014) Nuevas revisiones sobre la cultura material africana en el territorio argentino a partir de su visibilización en el registro arqueológico, así como casos de estudio en la provincia de Buenos Aires, pueden consultarse en Stadler (2017).

Otro campo es el de los proyectos y emprendimientos realizados en el área de la patrimonialización. Para un racconto y análisis de la inclusión de Argentina en el programa transnacional de La Ruta del Esclavo de la UNESCO, ver Annecchiarico (2018).

15 Un recorrido por distintos trabajos/autores y debates sobre el estudio de imágenes en torno a lo "negro" (en su sentido polisémico, amplio y contradictorio) en Argentina, puede encontrarse en el dossier coordinado por Lamborghini y Geler (2017).

16 Más información disponible en: https://docplayer.es/40805527Catedra-unesco-de-turismo-cultural-la-ruta-del-esclavo.html
} 
principales antecedentes, siguiendo su orden cronológico. Se trata de muestras y exposiciones exhibidas en distintas instituciones de gestión estatal, ya sea municipal o nacional con predominancia, aunque no exclusividad, de la exposición de obras plásticas sobre afroargentinos/ as y de material fotográfico alrededor de distintos ejes. Por ejemplo, en abril de 2010 se llevó a cabo la muestra "La historia negra del tango" en el Museo Casa Carlos Gardel, a través de la Subsecretaría de Cultura y la Dirección General de Museos, cuyo curador, antropólogo e investigador del Instituto Nacional de Musicología "Carlos Vega", Norberto Pablo Cirio, reunió y organizó documentos dirigidos a señalar la presencia y el rol de los afroargentinos como artistas destacados en este género emblemático de la cultura argentina. Este recorrido incluyó materiales relacionados con el candombe tradicional, así como fotografías, partituras y discos de destacados compositores e intérpretes de tango afroargentinos. El evento contó también con charlas, presentaciones de libros y tangos a cargo de la célebre cantante afroargentina Rita Montero. Por otro lado, hacia fines de ese mismo año, y en el marco de "La Noche de los Museos" de la Ciudad de Buenos Aires, se llevó a cabo en el Museo de la Mujer de Buenos Aires el evento "Mujeres afrodescendientes y su presencia en más de 200 años de historia". El mismo contó con la exposición de esculturas de una artista uruguaya, la proyección de videos, y una muestra plástica titulada "África Reproducciones de artistas africanos/as y europeos/as", que consistió en "representaciones y reflejos contemporáneos del África Negra, sus mujeres y la relación con la naturaleza, sus danzas, músicas y colores", según versaba en la promoción oficial. Si bien esta forma de discurso nos remite a las representaciones esencialistas de África, la temática general de la muestra, enfocada en las mujeres afro, daba cuenta del creciente interés en la intersección entre categorías étnico-raciales y de género. Alrededor de este eje, también se presentó una obra teatral realizada por un grupo de mujeres que tematiza la afrodescendencia en Argentina, dirigida por una dramaturga afrodescendiente y co-guionada por una antropóloga referente en estas investigaciones ${ }^{17}$, uno de cuyos libros se presentó en este ciclo (ver Geler, 2012).

Hacia fines de 2013 se realizaron otras dos muestras sobre la población afrodescendiente en/de Argentina. Así, la FotoGalería del Centro Cultural San Martín de la Ciudad de Buenos Aires contó con la muestra titulada "Los Afroargentinos. Fotografías 1860- 1960". Se trató de una muestra Colectiva de la Sociedad Iberoamericana de Historia de la Fotografía y formó parte de una muestra de fotografía histórica integrada por imágenes de siete colecciones privadas de estudiosos, fotógrafos y autores no identificados ${ }^{18}$. Ese año también se inauguró

\footnotetext{
17 Se trata de Alejandra Egido y de Lea Geler, respectivamente.

18 La muestra fue repuesta en los primeros meses de 2014. La curaduría estuvo a cargo de Abel Alexander (Sociedad Iberoamericana de Historia de la Fotografía) y Juan Travnik.
}

en el Salón Dorado de la Casa de la Cultura de la Ciudad de Buenos Aires una muestra de arte plástico que se prolongó de manera itinerante por distintas comunas de la ciudad durante 2014. Titulada "Héroes Afrodescendientes Argentinos Invisibilizados", consistió en una serie de cuadros que representan una selección de veinte personajes afroargentinoas/as desde el siglo XVIII hasta el siglo XXI; ya sea efemérides nacionales no reconocidas como afrodescendientes por la historia oficial, ya sea personajes desconocidos por el amplio público pero que ejercieron roles importantes, hasta artistas contemporáneos. Las obras fueron elaboradas por una artista plástica ${ }^{19}$ y el director general del proyecto fue el representante de una de las organizaciones políticas del "campo afro" (Fernández Bravo, 2013) local20.

Para finalizar con este repaso no exhaustivo, pero sí indicativo de los principales emprendimientos en el área, señalamos una muestra de otra índole, es decir; no tan dirigida al señalamiento de personas afroargentinas destacadas sino a la pedagogía sobre aportes culturales de la población africana y afrodescendiente a la identidad nacional argentina. A mediados de 2016, se realizó la exposición "Los afroporteños en la cultura nacional" realizada en el Museo del Libro y de la Lengua de la Biblioteca Nacional que tuvo como marco la muestra titulada "Antepasados" y se enfocó en la búsqueda de africanismos en el idioma de los argentinos. En este evento también se llevaron a cabo charlas a cargo de investigadores y activistas afrodescendientes.

Si bien las muestras realizadas evidencian un avance considerable en un área en la que hasta hace menos de una década había una total vacancia, es necesario continuar insistiendo sobre la necesidad de propender a representaciones no esencializantes de la "identidad" o bien, de las identificaciones -para destacar su carácter procesual-, de los afroargentinos/descendientes, dando lugar a la visibilización, también, de construcciones identitarias dinámicas.

Una contranarrativa que visibilice e integre la afrodescendencia a la historia argentina también debería esforzarse más enfáticamente por quebrar las barreras de la temporalidad y prolongar esta presencia hasta el presente, mostrando agencia en relación a determinado contexto histórico dentro del cual las acciones de los individuos resultarían inteligibles.

Esta contextualización exigiría mostrar también las representaciones sociales, vigentes en distintos momentos históricos y en la actualidad, sobre los afroargentinos, que casi nunca son favorables y que ayudan a entender las dinámicas reivindicativas -o de ocultamiento- emprendidas por sus miembros. De la

\footnotetext{
19 Se trata de la artista Mirta Beatriz Toledo.

20 Nengumbi Sukama, director del Instituto Argentino para la Igualdad, Diversidad e Integración (IARPIDI).
} 
mano de estas ideas, además de cuestionar la convicción de sentido común sobre la "desaparición" de los afroargentinos, se hace necesario poner en cuestión la negación de la existencia de racismo, en una sociedad donde se ocluyen las históricas vinculaciones entre dimensiones de raza y desigualdad social (Frigerio, 2006; Geler, 2016; Fernández Bravo, 2016; Picconi, 2016).

En la medida en que no se trata de un colectivo principalmente étnico sino étnico-racial -compuesto por grupos muy heterogéneos que, más que unidos por su "cultura" están igualados por la discriminación y la estigmatización que sufren en base a su fenotipo-, quizás la etnicización y exotización que los contextos multiculturalistas suelen traer aparejadas, no sean el mejor camino ni el más corto para su inclusión en la narrativa dominante de la nación y colaborar así con la obtención de derechos ciudadanos plenos.

Sin llegar a constituir un grupo étnico ni una comunidad única y homogénea, resulta de suma importancia sin embargo la presencia de un "núcleo duro" de afroargentinidad compuesto por un número todavía a precisar de familias que descienden de los africanos esclavizados en nuestro país, varias de ellas unidas por lazos de parentesco, y cuya memoria oral y patrimonio fotográfico es absolutamente necesario rescatar y valorizar ${ }^{21}$. Este tipo de material podría también ayudarnos a dejar de lado énfasis museológicos comunes sobre lo épico y lo exótico e incentivar una focalización en lo cotidiano y, quizás, más cercano.

Para esto, como suele destacarse en contextos de valoración creciente de la multiculturalidad y la interculturalidad, es necesario emprender procesos de colaboración con, y capacitación de, individuos u organizaciones afroargentinas que puedan intervenir en los procesos de musealización de su historia y patrimonio. De todas maneras, y para evitar idealizaciones, es importante recordar que toda (re)presentación, por ser una entre varias posibles, resulta en una tipificación y una reducción necesaria de una realidad multifacética.

La crisis de autoridad académica y museológica no se soluciona fácilmente con la "autorrepresentación", dado que, para usar una expresión cara a la antropología, no hay "uno" ni "unos", sino "muchos" "nativos" y la inclusión de algunos en detrimento de otros genera visiones también parciales. Los procesos de colaboración deberían ser ampliamente inclusivos. Museólogos, activistas políticos y culturales y académicos precisarían aprender a intercambiar puntos de vista de la manera más rica y menos conflictiva posible.

\footnotetext{
21 Una iniciativa que combinó investigación cuantitativa y cualitativa y se propuso, entre otros aspectos, enriquecer la escasez de datos censales oficiales (Censo 2010-INDEC), fue el proyecto "Certificar nuestra existencia", con foco en las mujeres afrodescendientes en el Partido de La Matanza (Geler, et. al, 2018).
}

La nueva narrativa que oriente guiones curatoriales debería ser asimismo lo más inclusiva posible. Debería tomar en cuenta la multiplicidad de actores afroargentinos y afrodescendientes y ser consciente de la variedad posible de sus identificaciones, así como la polisemia y ambigüedad de las categorizaciones raciales en nuestro contexto (Frigerio, 2006; 2009; Geler, 2016; Lamborghini y Geler, 2017; Picconi, 2016). Teniendo en cuenta esto último, así como la profundidad temporal del tema, surge la pregunta sobre cuál sería el rango (temporal y geográfico) de objetos a considerar pertinentes para ilustrar la historia, patrimonio y condición de la afroargentinidad. ¿Se incluirían también, de acuerdo a lo que sucede en otros países, objetos africanos o de la diáspora afroamericana?

¿Quiénes serían entonces los "representados"? ¿Los "afroargentinos"? ¿Los "afrodescendientes"? ¿Los "africanos"? En cada país y en cada momento estas categorías se procesan e interrelacionan -o no- de manera diferente. En los dos museos dedicados específicamente al tema en Brasil (Museu Afro Brasil de São Paulo, 2004, y Museu Afro-Brasileiro de Salvador, 1982) se incluyen piezas africanas. En el Museo Nacional Afroperuano, 2009, no. Un patrimonio considerado importante del Museu Afro-Brasileiro de Salvador son grandes tallas en paneles de madera realizados por un artista plástico argentino blanco (Carybé). Ni afro, ni brasilero. Su temática, sin embargo, se considera afrobrasilera.

Finalmente, y pensando en la proyección de un lugar museográfico permanente (es decir, no limitado a muestras temporales ocasionales), ¿es mejor -o hay una posibilidad de- concentrar los materiales en un sólo museo como los antes mencionados? ¿Sería mejor construir distintas salas permanentes en varios museos para forzar la visibilidad del material afroargentino y evitar el gueto museológico? ¿Enfatizar exposiciones temporales rotativas? ¿Intentar alguna gran muestra que resuma la historia y presencia de los afroargentinos, o muestras específicas, temáticas, más pequeñas? Es claro que estas alternativas no son necesariamente excluyentes.

\section{Consideraciones finales}

Tanto la bibliografía crítica sobre los museos en general, como la dedicada a las representaciones museográficas de África y la diáspora africana en particular enfatizan en la necesidad de una reflexividad institucional que posibilite superar las exclusiones y representaciones estereotípicas y desiguales del pasado. A partir de un recorrido por los temas, debates y advertencias de la museología crítica, este trabajo se dirigió a articular un análisis de dimensiones relativas a la Antropología de los Museos; el lugar de África y Afrolatinoamérica en las construcciones museográficas, y las relaciones entre representaciones afrodescendientes y museos en Argentina, con miras a realizar una colaboración propositiva y, sobre todo, interrogantes y reflexiones que iluminen problematizaciones necesarias en este último terreno. 
Dada la cantidad de omisiones y de información errónea que circula socialmente respecto de la afrodescendencia en Argentina, ciertamente, los guiones curatoriales en este campo deben esforzarse en ir explícitamente en contra de mitos como el de la desaparición de esta población -y las muestras y exposiciones realizadas al respecto han dado cuenta de esto-, pero también de la concomitante convicción sobre la ausencia de racismo en la sociedad. Se hace necesario continuar avanzando en la construcción de una contranarrativa que, oponiéndose explícitamente a la narrativa dominante de la nación "blanca europea" (Frigerio, 2006) -y proveyendo evidencia alternativa visible-, contribuya a desarmarla.

Para ello, habría que aprovechar al máximo el conocimiento producido por los estudiosos sobre el tema en las últimas décadas (ver Lamborghini, Geler y Guzmán, 2017), que en mucho adelanta al repertorio tradicional de interpretaciones, narrativas, historias e imágenes con el que se hacía referencia y se representaba a los afroargentinos en el pasado. Sin dudas este desafío va de la mano de otro importante; lograr una mayor articulación entre el campo académico y del activismo afro local.

Si, como bien señala Ames "la representación es un acto político, la curaduría es un acto político, el patrocinio es un acto político, trabajar en un museo es un acto político" (Ames, 1991: 13) -y, añadiríamos, una u otra colaboración "nativa" es un acto político-, "la curaduría y las políticas museológicas ya no pueden ostentar su neutralidad ni universalidad" (ídem.), como tampoco lo puede hacer la práctica académica. De esta manera, ya que toda (re) presentación es una reducción de una realidad compleja, quizás sería necesario que, junto con una mayor y explícita reflexividad, las exhibiciones sobre afrodescendencia en Argentina no dejaran dudas de su arbitrariedad, mediante una clara especificación del guión curatorial, la intención de la muestra, y del carácter contingente -y no definitivo ni consagratorio- de cualquier exhibición.

Buenos Aires, 19 de noviembre de 2018

\section{Agradecimientos}

Este trabajo ha sido realizado en el marco del P. BID PICT $2014 n^{\circ} 1211$.

\section{Referencias bibliográficas}

Agudelo, C. 2010. Génesis de redes transnacionales. Movimientos afrolatinoamericanos en América Central". En: Hoffmann, O. (coord.). Política e Identidad. Afrodescendientes en México y América. INAH, CEMCA, IRD. México: Ediciones de Buena Tinta.

Ames, M., 1991. Biculturalism in exhibitions. Museum Anthropology, $\mathrm{n}^{\circ}$ 2, Vol.15. p. 7-15.

Anderson, B., 1993. Comunidades imaginadas. Reflexiones sobre el origen y la difusión del Nacionalismo, México, FCE.
Annecchiarico, M., 2018. El patrimonio cultural afroargentino: un análisis del programa "ruta del esclavo" UNESCO en Argentina Revista del Museo de Antropología 11 (1): 229-240.

Arnoldi M.J., 1999. From the Diorama to the Dialogic: A Century of Exhibiting Africa at the Smithsonian's Museum of Natural History." Cahiers d'Études Africaines, nº 155/156, Vol. 39.

Bayardo, R., 2005. Museos entre identidades cristalizadas y mercados transnacionales. Anais do Museu paulista, $n^{\circ} 2$, Vol. 13, jul-dez, Sao Paulo. p. 49-64.

Crampton, A., 2003. "The art of nation-building: (re)presenting political transition at the South African National Gallery". Cultural Geographies, n², Vol.10. p. 218-242.

De Varine, H., 1974. Los museos en el mundo, Editorial Salvat.

Dibley, B., 2005. The museum's redemption. Contact zones, government and the limits of reform. International Journal of Cultural Studies, n 1, Vol. 8. p. 1-26.

Fraser, N. 1997. "¿De la redistribución al reconocimiento? Dilemas en torno a la justicia en una época "postsocialista"". En: Justitia Interrupta: Reflexiones críticas desde la posición "postsocialista". Bogotá: Siglo de Hombres Editores.

Fernández Bravo, N., 2013. “QQué hacemos con los afrodescendientes?" Aportes para una crítica de las políticas de la identidad. En Guzmán, F. y Geler, L. (Eds.). Cartografías afrolatinoamericanas. Perspectivas situadas para análisis transfronterizos, pp.241-260. Buenos Aires: Biblos.

Fernández Bravo, N. (2016). El regreso del cabecita negra. Ruralidad, desplazamiento y reemergencia identitaria entre los santiagueños afro». En: F. Guzmán, L. Geler y A. Frigerio (Eds.), Cartografías Afrolatinoamericanas 2 (161-182). Buenos Aires: Biblos.

Frigerio, A., 2006. "'Negros" y "Blancos" en Buenos Aires: Repensando nuestras categorías raciales. Temas de Patrimonio Cultural, 16.

Frigerio, A., 2009. Luis D'Elia y los negros: identificaciones raciales y de clase en sectores populares. Claroscuro, 8, p. 13-44.

Geler, L., 2012. Afrolatinoamericanas... Una experiencia de subversión estereotípica en el Museo de la Mujer de Buenos Aires. Horizontes Antropologicos, 18, 38. p. 343-372.

Geler, L., 2016. Categorías raciales en Buenos Aires. Negritud, blanquitud, afrodescendencia y mestizaje en la blanca ciudad capital. Runa. Archivo para las ciencias del hombre. p. 37, 71-87.

Geler, L., Egido, A., Recalt, R., y Yannone, C., 2018 Mujeres afroargentinas y el proyecto Certificar nuestra existencia. Una experiencia de trabajo multidisciplinar en Ciudad Evita (Gran Buenos Aires). Población \&Sociedad Vol. 25 (2), 2018, pp. 28-54. DOI: http://dx.doi.org/10.19137/pys-2018-250202.

Ghidoli, M. de L., 2016. Estereotipos en negro. Representaciones y autorrepresentaciones de afroporteños en el siglo XIX. Rosario: Prohistoria. 
Greene, S. 2007. "Entre lo indio, lo negro, y lo incaico: The Spatial Hierarchies of Difference in Multicultural Peru". Journal of Latin American and Caribbean Anthropology, 12 (2), .441-474.

Hale, Ch., 2004. "Rethinking Indigenous Politics in the Era of the "Indio Permitido". Nacla Report on the Americas, 38 (2), .16-21.

Jones, A. L., 1993. Exploding Canons: The Anthropology of Museums, Annual Review of Anthropology, 22. 201-220.

Khan, M., 1995. Heterotopic dissonance in the museum representation of pacific island cultures. American Anrhropologist, 2, 97. 324-33.

Lamborghini, E. y Geler, L., 2016. Imágenes racializadas: políticas de representación y economía visual en torno a lo "negro» en Argentina, siglos XX y XXI. Introducción, conclusiones y edición del dossier. Corpus. Archivos virtuales de la alteridad americana, 6, 2. 1-13 y 33-31. Recuperado de: https://corpusarchivos. revues.org/1614

Lamborghini, E., Geler, L. y Guzmán, F., 2017. Los estudios afrodescendientes en Argentina: nuevas perspectivas y desafíos en un país «sin razas» Tabula Rasa. Convocatoria: «Los estudios afrodescendientes en América Latina: un campo en constante expansión y movimiento», Bogotá, Colombia, No.27, p. 68-101. https://doi.org/10.25058/20112742.445

Lopes Ma. M. y Podgorny I., 2000. The shaping of Latin American Museums of natural history, 1850-1890. OSIRIS, Second series, Vol. 15.

Lleras Figueroa, C., 2009. Etnicidad, investigación y representación en la exposición Velorios y Santos Vivos. Comunidades negras, afrocolombianas, raizales y palenqueras. Cuadernos de Curaduría, Museo Nacional de Colombia, novena edición, julio.

Macdonald, S. J., 2003. Museums, national, postnational and transcultural identities. Museum and society, $n^{\circ} 1$, Vol. 1. p. 1-16.

Mithlo, N. M., 2003. Staging the Indian: The Politics of Representation. The Tang Teaching Museum and Art Gallery at Skidmore College. February 2, 2002-June 2, 2002. American Anthropologist, n 1, Vol. 105, march. p. 153- 161.

Montero, P., 2012. Multiculturalismo, identidades discursivas e espaço público, Sociologia\&Antropologia, vol.2 no.4 pp. 81-101.

Moser, S., 2010. The devil is in the detail: Museum Displays and the Creation of Knowledge, Museum Anthropology, 1, 33. 22-32.

Pegoraro A., 2005. "Instrucciones" y colecciones en viaje. Redes de recolección entre el Museo Etnográfico y los Territorios Nacionales. Anuario de estudios de antropología social. Centro de antropología social- IDES. Buenos Aires. p. 49-64.

Pegoraro A., 2010. Le mokomokai du Musée Ethnographique Juan B. Ambrossetti (1910-2004), Gradhivia, Musée du quai Branly, 2010/1, nº 11.

Pérez Gollán, J. A., 1997. Proyecto para el Museo Etnográfico (agosto 1987), Noticias de Antropología y Arqueología, 17.

Pérez Gollán J. A. y Dujovne M., 1996. El Museo Etnográfico: funciones y balance de una gestión, Runa, Archivo para las Ciencias del Hombre, Vol. XXII, Buenos Aires.

Pérez Gollán J. A. y Dujovne M., 2001. De lo hegemónico a lo plural: un museo universitario (Museo Etnográfico, Universidad de Buenos Aires). Entrepasados. n 20-21. Año X.

Pérez Ruiz, M. L., 1998. Construcción e investigación del patrimonio cultural. Retos en los museos contemporáneos. Alteridades, 6, 8.

Philips, R. B., 2002. Where Is "Africa"? Re-Viewing Art and Artifact in the Age of Globalization. American Anthropologist, 3, 104.

Picconi, M. L. (2016). Los colores de la discriminación. Procesos de reemergencia afrodescendiente en Córdoba. Córdoba: Babel.

Roca, A., 2008. Los usos del tiempo en el espacio de un museo etnográfico". En: Roigé, X., Fernández, E.; Arrieta, I. (Coord.) El futuro de los museos etnológicos, consideraciones introductorias para un debate. Barcelona: Laia, p. 231-246.

Saloni, M., 2000. Redefining the ethnographic object: An anthropology museum turns fifty", American Anthropologist, 3, (102), 593-597.

Santos, M.S., 2003. Museums without a past: The Brazilian case (State University of Rio de Janeiro, Brazil), International journal of cultural studies, 2 (6), 180-201.

Schávelzon, D., y Zorzi, F.,2014. Arqueología Afro-argentina: un caso de miopía racista en el mundo académico al inicio del siglo veinte, La Revista de Estudios Panafricanos, 7(7), 93-107.

Silverman, H., 2004. Subverting the Venue: A Critical Exhibition of Pre-Columbian Objects at Krannert Art Museum. American Anthropologist, 106, 4.

Stadler, N., 2017. "La Cultura Material Afro en la Arqueología Argentina. Expectativas para un caso de estudio en Quilmes (Buenos Aires)", En: Lamborghini, E., Martino, M.C., y Martínez Peria, J.F., (comps.): Estudios afrolatinoamericanos 3: Actas de las Quintas Jornadas de GEALA; Ediciones del CCC Centro Cultural de la Cooperación Floreal Gorini, CABA Libro digital, PDF.

Steiner C., 1995. Museums and the politics of nationalism. Museum Anthropology, 2,19.

Thomas, N., 2010. The Museum as a method. Museum Anthropology, Vol. 33, Issue 1, p. 6-10.

Udvardy, M., Giles L., and Mitsane J., 2003. The transatlantic trade in african ancestors: mijikenda memorial statues (Vigango) and the ethics of collecting and curating non-western cultural property. American Anthropologist, n³, Vol. 105. p. 566-580.

Vogel, S., 1991. Always True to the Object, in Our Fashion. In: Karp, I \& Lavine, S. (eds). Exhibiting Cultures: The Poetics and Politics of Museum Display, Smitsonian Institution, Washington.

Yelvington K. A., Goslin N. G. and Arriaga W., 2002. Whose History?: Museum-making and struggles over ethnicity and representation in the Sunbelt. Critique of Anthropology, 3, 22, 344-378. 